\title{
Menstrual Practice Needs Scale (MPNS): Reliability and Validity of the Turkish Version
}

\author{
Pınar Irmak Vural (D), Yeliz Varışoğlu (D) \\ Department of Nursing, İstanbul Medipol University, Faculty of Health Science, İstanbul, Turkey
}

ORCID iDs of the authors: P.I.V. 0000-0002-8070-2840; Y.V. 0000-0002-6350-72I8.

Cite this article as: Vural PI, Varışoğlu Y. Menstrual Practice Needs Scale (MPNS): Reliability and Validity of the Turkish Version. Cyprus J Med Sci. 2021; 6(4): 295-302.

\section{BACKGROUND/AIM}

Menstrual practices have actions undertaken to manage menstrual bleeding, including accessing, storing, and transporting acceptable menstrual materials, changing and disposing of used materials, washing and drying of reusable materials, and cleaning the hands, genitals, and body. This study aims to conduct the reliability and validity study of the Turkish version of the Menstrual Practice Needs Scale (MPNS), which determines the menstrual practices and needs.

\section{MATERIAL and METHODS}

This methodological study was conducted with 446 university students in Istanbul in Turkey from June to July 2020.

\section{RESULTS}

In this study, the mean age of the participants was $19.93 \pm 2.34$. The confirmatory factor analysis showed a good fit. Cronbach's $\alpha$ of this scale was 0.78 . The test-retest reliability coefficient was $r=.661$. The content validity index was calculated as 0.89 . In this study, the Kaiser Meyer Olkin value was 0.819, which is considered very good. The result of Bartlett's Test of Sphericity was $\chi^{2}=4,894.399, P<$ .001 for MPNS. Item-total correlation factor loadings varied from 0.24 to 0.94 . According to the item-total correlation, one item was removed.

\section{CONCLUSIONS}

The findings suggest that the Turkish language version of the MPNS is valid and reliable.

Keywords: Menstrual Practice Needs Scale, nursing, reliability, validity

\section{INTRODUCTION}

Menstruation is a physiological process that is experienced from the ages of menarche to menopause.' Women's strategies to cope with menstrual period needs and menstrual practices may vary by age and culture. Menstrual hygiene management is influenced by the educational, socioeconomic, and cultural status of women. The challenges encountered by menstruating women and adolescent girls in low-resource environments indicated adverse effects on many areas of life, such as health status, education, employment, and also wellness. ${ }^{2}$

Girls usually manage menstruation with methods that could be unhygienic or inconvenient, especially in poorer environments. Girls in low- and middle-income countries have challenges coping with menstrual needs due to a lack of money or social support. Thus, in this case, girls take suboptimal care or investigate improper ways of sourcing menstrual materials. Menstrual needs become more challenging to cope with water, hygiene, and sanitation problems. Thus seen in women and young girls, gynecological infections, such as vaginal secretion and itching associated with poor hygiene conditions. ${ }^{3-5}$ There are very few empirical studies in the literature that have measured the extent and intensity of difficulties in managing the menstrual needs of young girls, which has remained under-researched. Few studies have examined causal relationships to confirm the effectiveness of attempts to manage menstrual hygiene to maintain health and attend school. ${ }^{3}$ Young girls undertake a variety of actions and use a range of environments to manage their menstruation. They also vary in their satisfaction and concerns about these practices. Menstrual practices are the actions undertaken to manage menstrual bleeding, such as accessing, storing, and transporting acceptable menstrual materials (e.g., 
cloth and pads), changing and disposing of used materials, washing and drying of reusable materials, and cleaning the hands, genitals, and body. In assessing menstrual practices, it is also important to capture the environments women may use to undertake these practices, that is, the spaces women use to change materials, dispose of them, and clean their bodies and materials. There are other actions that women and girls may undertake to care for their bodies during menstruation, such as pain relief or accessing information about the menstrual cycle. However, pain and pain management experiences and menstrual experience of knowledge and social support are separate concepts. ${ }^{6}$ Perceptions of menstrual practices, positive or negative, may reflect the practices themselves but are also dictated by women's perspectives and past experiences, and their context and the expectations of others in their community. In some cultures, menstruation is seen as taboo, and women are labeled as "dirty," forced into seclusion or not sent to school, not participating in some of the daily activities, such as not cooking, making it difficult to manage menstrual practices. ${ }^{7}$ The menstrual practices were undertaken by women and girls, that is, the behaviors they undertake to manage their menstrual bleeding, which are one of the most frequently assessed outcomes in menstrual health research and program monitoring. Most of the studies and practices aimed to investigate menstrual needs, health, and hygiene have focused on improving menstrual practices of women and girls. ${ }^{8-10}$ The Menstrual Practice Needs Scale (MPNS) was developed using a holistic and woman-centered approach. It offers a way to capture women's and girls' perceptions of how they manage their period. That is, if they felt their practices and environments met their needs. The MPNS provides a way to objectively measure menstrual experiences and test if interventions achieved this desired effect. 6 There was not any tool for measuring menstrual experiences in Turkish. Therefore, this study aims to evaluate the reliability and validity of the Turkish version of the MPNS in university girl students.

\section{MATERIAL and METHODS Research Type}

This present study had a methodological design.

\section{Data Collection and Tools}

This study was conducted on first and second-year students in the nursing department of a university in Istanbul in Turkey between June and July 2020. Data collection tools were

\section{Main Points}

- The Turkish version of the MPNS is a valid and reliable measurement scale in the assessment of self-perceived menstrual hygiene needs and practices.

- MPNS measures the extent to which respondents' menstrual management practices and environments were perceived to meet their needs during their last period.

- MPNS items ask about perceptions of comfort, satisfaction, adequacy, reliability, and worries and concerns during the last menstrual period.

- MPNS provides a way for researchers and practitioners to understand if the menstrual management and environmental needs of their population are being met. designed using a google form. In the collection of the data, two forms were used, the participant information form, which was prepared by the researchers in light of the literature and similar works and the MPNS.

\section{Participant Information Form}

The participant information form consisted of 15 questions questioning descriptive and gynecological characteristics of participants. ${ }^{2,4,11}$

\section{Menstrual Practice Needs Scale}

MPNS, designed by Hennegan et al.," consists of 36 items, including materials, hygiene, and practices used in menstrual cycle management. The scale focuses on the experience of participants in women's last menstrual period and explores the experiences of the practices and the environments used to manage their menstrual period. Scale items include comfort, satisfaction, adequacy, reliability, and concerns in the last menstrual period."

The MPNS contains 36 items in total, 28 items that can be applied to all participants, and the remaining eight items for those with washing and drying experience for reuse of menses. Subscales and total scores are calculated as average scores to support the accessibility of girls. The subscales are listed as follows: "material and home-environment needs" (II questions, $\alpha=$ 0.79), "transportation and school environment needs" (five questions, $\alpha=0.66$ ), "material reliability concerns" (three questions, $\alpha=0.5 \mathrm{l}$ ), "change and disposal distrust" (nine questions, $\alpha$ $=0.74$ ), "reuse needs" (five questions, $\alpha=0.66$ ), and "reuse distrust" (three questions, $\alpha=0.47$ ). Whether the products are home or school-based was relevant in managing the menstrual period. Higher scores from MPNS mean more positive experiences, and the scores are associated with the probability of being absent from school during the menstrual period $(95 \% \mathrm{Cl}$ 1.52 to $4.50, \mathrm{OR}=2.62$ ). As a reliability test, test-retest results were moderate in the original form of MPNS (total score of intraclass correlation coefficient $=0.69$ ). Scoring on a "4-point Likert type scale": never, sometimes, usually, and always (0-3 points) for positively and negatively encoded items, the reverse was calculated."

\section{Participants and Sample Size}

Larger sample sizes in studies increase the generalizability of results reached through factor analysis. ${ }^{12}$ A reasonable 'observations to variables' rate is $10: 1$, given that this scale had 28 items, and the expected sample size was 280 participants. This study was conducted with 446 young girls aged $18-25$ who volunteered to participate and spoke Turkish.

\section{Data Statistics}

The data collected from the young girls by google form were analyzed using the Statistical Package for the Social Sciences (SPSS) version 18.0 (IBM SPSS Corp; Armonk, NY, USA) and AMOS 23 (SPSS Inc.; Chicago, IL, USA) programs. In the reliability analysis, the Pearson correlation coefficient was assessed using a test-retest test method in the evaluation of time invariance. For internal consistency assessment, the itemtotal correlation coefficient and internal consistency coefficient were calculated. In this context, the Pearson correlation coefficient and Cronbach's $\alpha$ reliability coefficient were tested. About the content validity of this scale, the Lawshe technique was used in evaluating expert opinions, and confirmatory 
Table I. Mean, Standard Deviation, and Distributional Characteristics of Individual's Menstrual Practice Need Scale Subscales ( $n=446$ )

\begin{tabular}{|c|c|c|c|c|c|c|}
\hline MPNS Subscales & Mean (SD) & Min-Max & Skew & Kurtosis & SE & Cronbach's $\alpha$ \\
\hline Material and home environment needs & $2.65(0.29)$ & $0-3$ & -1.706 & 2.328 & 0.11 & 0.80 \\
\hline Transport and school environment needs & $2.17(0.62)$ & $0-3$ & -0.523 & -0.272 & 0.22 & 0.75 \\
\hline Material reliability concerns & $1.54(0.75)$ & $0-3$ & -0.018 & -0.812 & 0.27 & 0.67 \\
\hline Change and disposal insecurity & $2.4 \mathrm{I}(0.46)$ & $0-3$ & -1.357 & 2.754 & 0.02 & 0.72 \\
\hline Total score & $2.19(0.35)$ & $0-3$ & -0.288 & 0.234 & 0.01 & 0.78 \\
\hline
\end{tabular}

Abbreviations: SD, standard deviation; $\mathrm{SE}$, standard error of the mean.

factor analysis (CFA) was applied in evaluating structure validity. The statistical significance level was determined as $P<.05$.

Before data analysis, a pilot study was conducted $(n=35)$. According to the pilot study, the items of the scale related to the subscales of "reuse needs" and "reuse distrust" were determined. The present study was followed on 28 items of the MPNS that were applied to all participants."

It was deemed appropriate to conduct an exploratory factor analysis (EFA) to test the Turkish cultural validity. The content validity check was examined to determine whether all items could be included in the Turkish version of the scale. In addition, the skewness and kurtosis indices were calculated to test the normality of the distribution. ${ }^{13}$ Descriptive characteristics of each MPNS subscale are indicated in Table I and revealed no indication of extreme skew or kurtosis based on Kline's thresholds of 3 (skew) and 10 (kurtosis).

\section{Ethics}

Ethical committee approval was received from the Istanbul Medipol University Noninvasive Clinical Research Ethics Committee (approval number: 47I-I0.06.2020 and institutional permission was obtained to conduct this study. In addition, the girls who volunteered to participate in the present study were informed about the aim of this study. A written informed consent was obtained from all individual participants included in this study.

\section{RESULTS \\ Participants}

Data were collected from 446 participants at the scale validity and reliability phase. The mean age of the participants was $19.93 \pm 2.34$, the mean age of menarche was 13.II \pm 1.29 , and the duration of menstruation was 5 days. The findings obtained in this study showed that $90.8 \%$ of the participants experienced pain during menstruation and $78.2 \%$ took painkillers.

\section{Validity}

Language validity: To evaluate the Turkish cultural appropriateness of the scale and the understandability of each item, the translated version of the scale was submitted to a group of 10 academicians consisting of nurses and midwives using an e-mail. The content validity criterion was specified to be 0.62 in the literature. ${ }^{14}$ Based on the Lawshe technique, according to the feedback of these 10 academic experts, it was determined that none of the items of the scale was less than 0.62. No item was removed at this stage.

Content validity: The Davis technique was used to evaluate validity while determining content validity, which is another cri- terion. After the translation process from Turkish into English, the scale was presented to academic experts for content validity. Each item in the MPNS was evaluated on a 4-point scale: the item was scored appropriately to not appropriate (4-I). Based on the Davis technique according to the literature, it is appropriate to have the content validity index $(\mathrm{CVI})$ above 0.80 according to the academic experts who provide opinions. ${ }^{15}$ The determination of $\mathrm{CVI} 0.89$ for this scale demonstrates that content validity is adequate.

Construct validity: Two analyses were conducted to test the MPNS construct validity; these are EFA and CFA. When the Kaiser-Meyer-Olkin (KMO) value of this scale was tested, it was determined to be 0.819 , and this result indicates that it is very good for factor analysis. Besides, the result of Bartlett's test of Sphericity was $\chi^{2}=4,894.399, P<.00$ l for MPNS.

Confirmatory factor analysis: CFA is a process for creating factors based on observed variables through a preconstructed model. CFA has been tested for the compatibility of the Turkish language factors. The Chi-square value is the most basic measurement used to test the fit of the model. The goodness of fit indexes and the Chi-square continuity correction ( $2 \mathrm{~N}+/ \mathrm{df}$ ) test were applied to the subscales established in the model to test the model. In this study, with CFA, the fit indices were chisquare/degree of freedom $(\mathrm{CMIN} / D F)=2.63$, comparative fit index $(\mathrm{CFI})=0.88$, the goodness of fit index $(\mathrm{GFI})=0.89$, root mean square error of approximation $(R M S E A)=0.06$, and standardized root mean square residual (SRMR) $=0.044$ (Table 2). With these test results, the four-factor structure was confirmed. Item-total correlation factor loadings of the scale (path coefficients) varied from 0.24 to 0.94 (Figure I). The path diagram of the established model is presented in Figure I.

\section{Reliability}

Internal consistency: Cronbach's $\alpha$ reliability coefficient was calculated to test the reliability of the scale. A Cronbach's $\alpha$ value within $0.70-0.90$ indicates the most suitable internal validity. ${ }^{16}$ In this study, Cronbach's $\alpha$ value was determined as 0.76 , which was acceptable for internal validity. The corrected item-total correlation of this scale was analyzed, which ranged from 0.14 to 0.68 and decided to be an acceptable level (Table 3). According to this result, the 28th item ("When at school, I worried that someone would harm me while I was changing my menstrual materials.") was removed because the total correlation value of this item was under 0.30 .

After the 28th item was removed, item-total correlation values of the items in the scale varied from 0.313 to 0.683 , and Cronbach's $\alpha$ value increased to 0.78 . The statistical analysis of the 
Table 2. CFA Results of the Fit Index for Menstrual Practice Needs Scale $(n=446)$

$\begin{array}{lcccc}\text { Indexes } & \text { Good Fit } & \text { Acceptable Fit } & \text { Model Results } & \text { Decisions } \\ \text { CMIN/DF } & \chi^{2} / \mathrm{df}<3 & \chi^{2} / \mathrm{df}<5 & 2.63 & \text { Good fit } \\ \text { GFI } & >0.90 & >0.85 & 0.89 & \text { Acceptable fit } \\ \text { CFI } & >0.95 & >0.90 & 0.88 & - \\ \text { RMSEA } & <0.05 & <0.08 & 0.06 & \text { Good fit } \\ \text { SRMR } & <0.05 & <0.08 & 0.044 & \text { Good fit }\end{array}$

Note: $\chi^{2}$ : Chi-square fit test; $\mathrm{df}$ : degree of freedom.

Abbreviations: CMIN/DF: Chi-square/degree of freedom; CFA: confirmatory factor analysis; CFI: comparative fit index; GFI: goodness of fit index; RMSEA: root mean square error of approximation; SRMR: standardized root mean square residual.

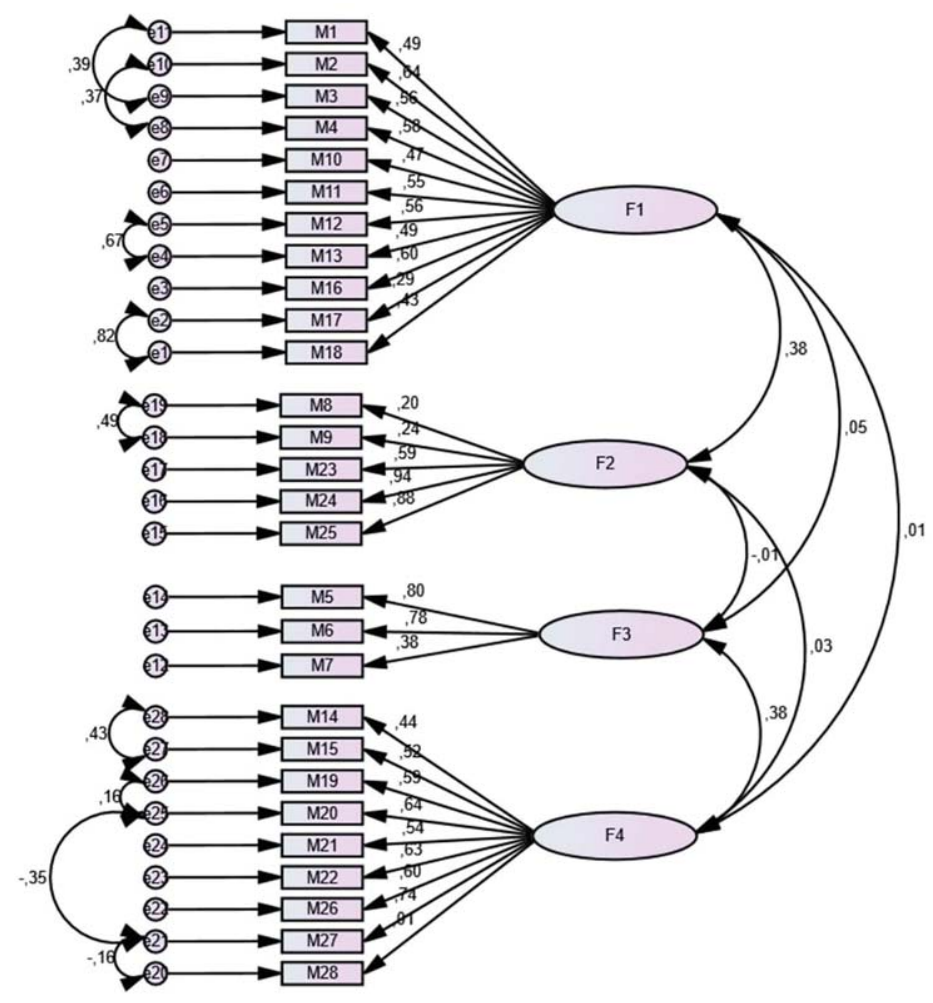

FIGURE I. Confirmatory factor analysis of MPNS: path coefficients and error variances $(N=446)$. Abbreviations: $M$, item; F, factor. P-value: .00.

corrected item-total correlations and Cronbach's $\alpha$ if item deleted are given in Table 4.

Test-retest reliability: This scale's test-retest reliability was performed. Test-retest analysis shows that a scale applied in the reliability study of the scale is determined to be invariant over time by readministering it to the same group in a certain time interval (between 2 and 4 weeks). ${ }^{17,18}$ Thereby, the correlation value between the first and second application scores of the MPNS was determined to be $r=0.661$, with a significant difference with a $P<.00$ l level. This finding implies that the first and last application scores results applied with a 4-week interval were similar (Table 5).

\section{DISCUSSION}

The adaptation of the MPNS into Turkish and the findings of the Turkish version of the scale were discussed in this section. The findings of this study were discussed in the following head- ings, discussion of the results on the reliability and validity of the MPNS.

\section{Discussion of the Results on the Reliability of the MPNS}

Reliability is a concept that reveals the consistency of all items with each other in a measurement tool and their homogeneity in measuring the formation under consideration. Internal consistency evaluates the reliability of a scale, which is one of the common methods. Usually, Cronbach's $\alpha$ coefficient should be calculated to evaluate the internal consistency of Likert-type scales. ${ }^{19}$ In this study, Cronbach's $\alpha$ coefficient, item total correlation, and test-retest analysis were used to determine the reliability of the MPNS. Cronbach's $\alpha$ coefficient of the MPNS was 0.78. Also, the subscales' Cronbach's $\alpha$ coefficients of the "Material and home environment needs" was 0.73, "Transport and school environment needs" was 0.76, "Material reliability concerns" was 0.69 , and "Change and disposal insecurity" was 0.69 . Hennegan et al." stated that Cronbach's $\alpha$ coefficient was 
Table 3. Item Subscale and Total Score Correlations of the Menstrual Practice Needs Scale Total and Subscales $(n=446)$

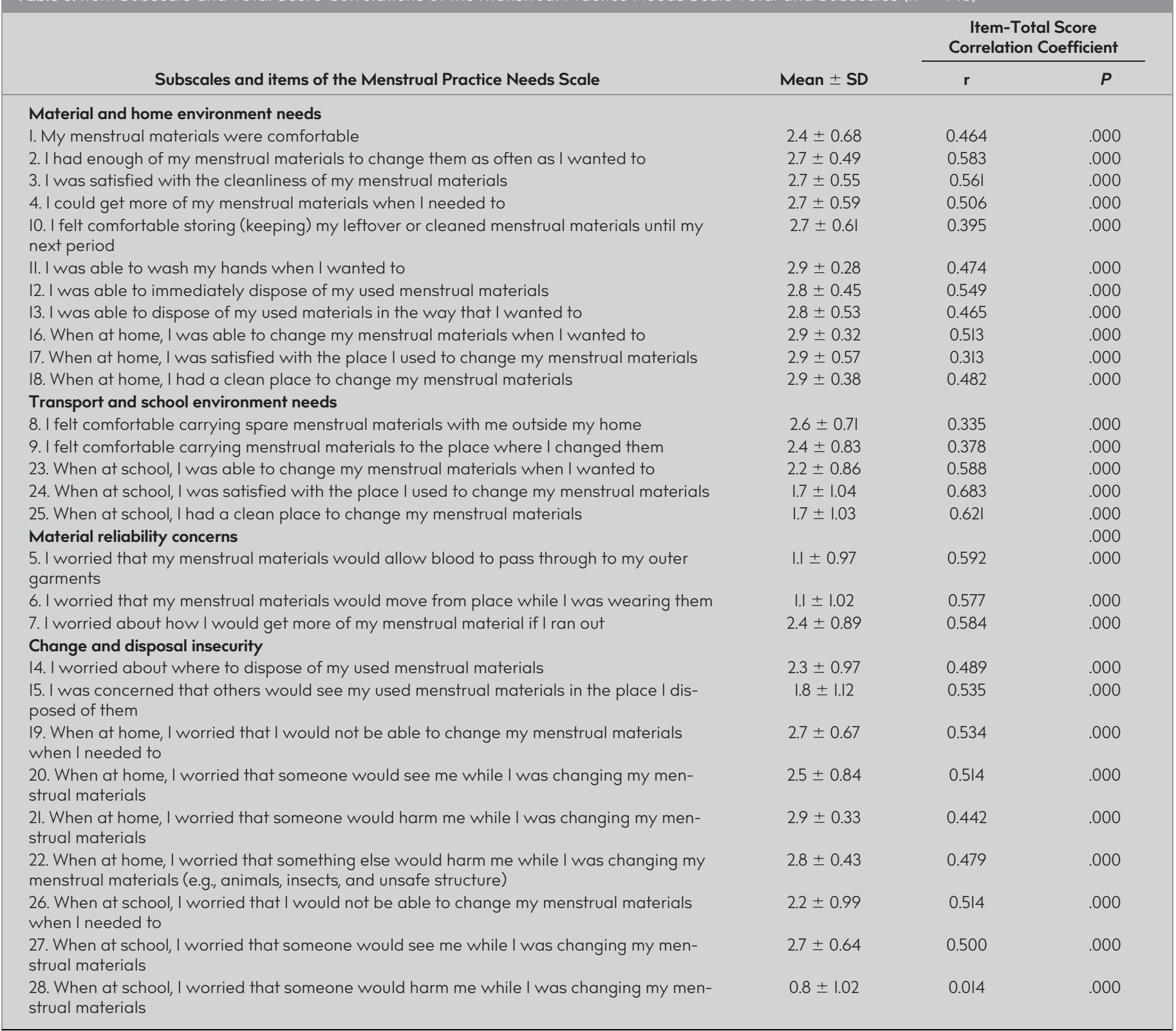

Abbreviations: SD: standard deviation.

0.77 for the MPNS. Subscales Cronbach's $\alpha$ coefficients of the "Material and home environment needs" was 0.79, "Transport and school environment needs" was 0.66, "Material reliability concerns" was 0.51 , and "Change and disposal insecurity" was 0.74 in the original version."

As another test, the item-total score correlation was used to evaluate internal consistency. The average of the item total score correlation coefficients gives the reliability of the scale. This method explains the relationship between the scores obtained from the scale items and the total score of the test. The total score correlation of an item of scales should be at least 0.30, according to the literature. ${ }^{17}$ The findings obtained in this study showed that the total item score correlation of MPNS was within 0.014 to 0.683 (Table 3). Items with low coefficients should be removed from the scale.
According to this result, the 28th item was seen under 0.30 and removed.

Another consistency criterion is test-retest reliability. This provides the capability of measuring the results of the time difference. The scale is applied under the same conditions on the same subjects at two different times (2-4 weeks or 10-20 days). The correlation between observations at two different times will be an indicator of reliability. Eventually, this correlation coefficient is wanted to be positive and high. Besides, in the literature, it is deemed appropriate to have at least 30 participants in these tests. ${ }^{17,20}$ Based on the literature, in this study, the scale was reapplied four weeks later to 44 participants. The test-retest correlation value result of the scale was $r=.66$, and also a significant relationship was found at $P<.00$ l significance level (Table 4). The findings obtained in this study indicated 
Table 4. Explanatory Factor Analysis Results for Menstrual Practice Needs Scale $(n=446)$

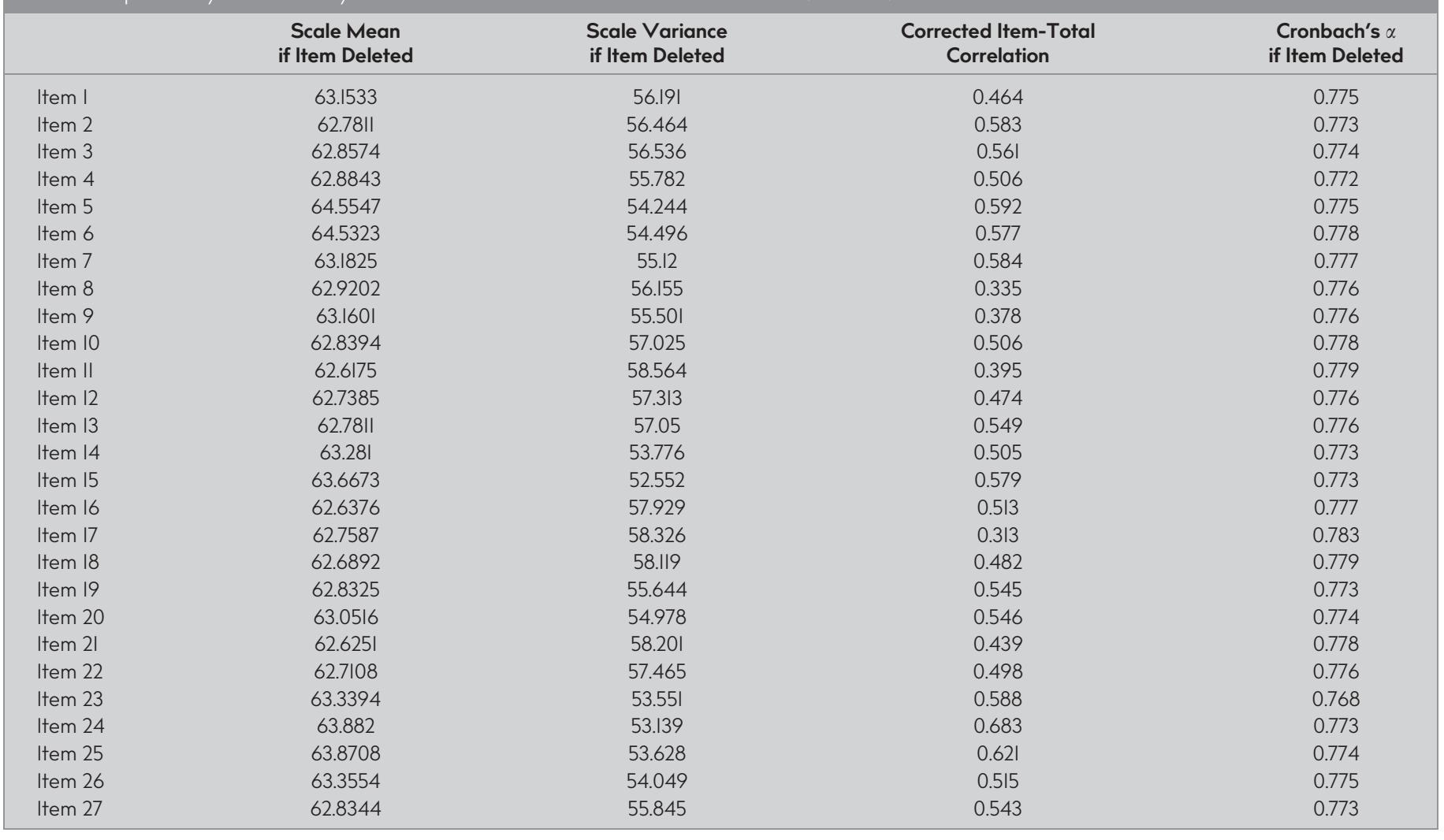

Table 5. Comparison of Test and Retest Mean Scores of the Menstrual Practice Needs Scale and Subscales and Correlations $(n=44)$

\begin{tabular}{|c|c|c|c|c|c|c|}
\hline Subscales & $\begin{array}{l}\text { First Test } \\
\text { Mean (SD) }\end{array}$ & $\begin{array}{l}\text { Second Test } \\
\text { Mean (SD) }\end{array}$ & $t$ & $P$ & $\mathbf{r}$ & $P$ \\
\hline Material and home environment needs & $2.44(0.41)$ & $2.48(0.21)$ & -0.616 & .541 & 0.563 & .000 \\
\hline Transport and school environment needs & $2.09(0.63)$ & $2.16(0.57)$ & -0.539 & .592 & 0.637 & .000 \\
\hline Change and disposal insecurity & $2.38(0.49)$ & $2.51(0.33)$ & -0.946 & .354 & 0.647 & .000 \\
\hline Total score & $2.11(0.31)$ & $2.18(0.36)$ & -0.695 & .495 & 0.661 & .000 \\
\hline
\end{tabular}

that the test and retest results of MPNS were similar. Also, the test-retest results of the original version of the MPNS were stated as moderate $(r=.69)$." Briefly, this scale showed good internal consistency and acceptable test-retest reliability the findings obtained from the analysis of the reliability.

\section{Discussion of the Results on the Validity of the MPNS}

In this study, to have content validity, the Davis technique was used. Based on specialists' opinions, the CVI value was 0.89, and it was determined that there was a consensus among the academic experts. In the pilot study, the questions that the participants had difficulty understanding were rearranged, and the scale was made easier to understand. Also, pilot implementation was applied to 35 students, with the draft form created finally. Therefore, in this process, no items were removed from this scale based on content validity.

The KMO test measures sampling adequacy and deals with sample size. It is an index that compares the size of the observed correlation coefficients with the size of the partial correlation coefficients. It can be said that the higher the ratio, the better the data set is for factor analysis. The KMO value of 0.90 is accepted as excellent, 0.80 indicates a very good value, and the lower values mean weaker. ${ }^{12} \mathrm{KMO}$ value of this study was 0.819 , which is very good. In the original version of MPNS, the $\mathrm{KMO}$ value was found 0.72." Bartlett's test of sphericity is an indicator of suitability for factor analysis. According to the Chisquare value in Bartlett's test of sphericity, the data were correlated with each other, and also, the result of Bartlett's test of sphericity was tested to be $\chi^{2}=4,894.399, P<.001$ for MPNS. As a result of these tests, the correlation matrix, sample size, and data were appropriate for factor analysis in this study.

CFA, which is used in scale adaptation studies, is the best way to test whether a scale whose construct validity has been tested preserves this structure in the language and culture to be adapted. While it is expected that the Chi-square value is not significant for a model to be acceptable, it is seen that it generally means in practice. This is because this value is very 
sensitive to the sample size. Instead, when the Chi-square value is divided by the degrees of freedom, the resulting value is two or less, and five or less indicates that the model has an acceptable goodness of fit. The CFA explains that the measures of RMSEA, SRMR, CFI, GFI, and the $2 \mathrm{~N}+$ / df value were at wanted levels. ${ }^{21}$ In this study, the value obtained by dividing the Chi-square value by the degrees of freedom according to the CFA results was 2.63; this value showed that the model has a goodness of fit. The other fit index values were RMSEA $=0.06, \mathrm{CFI}=0.88, \mathrm{SRMR}=$ 0.044 , and $\mathrm{GFI}=0.089$. In the original version of MPNS, CFA supported a good model fit for the 28 items (RMSEA $=0.028-0.029$, CFI = 0.957-0.959)." The results of this study showed that the factor loading and interpretation variance were strong, consistent with EFA results, and had a good factor structure. In summary, the findings from this study demonstrated that the MPNS is a suitable instrument for evaluating practices and needs of menstruation for Turkish university girl students.

The MPNS measures menstrual hygiene experiences and prioritizes participant perceptions of capacity above the researcher determined sufficient menstrual period practices. A scale enables the individual to evaluate the status of her perceived menstrual hygiene and needs. Using this scale, the relationship between menstrual practices in cross-sectional and longitudinal studies with education, health, well-being, and social support can be determined." This study contributes to the literature through its Turkish version of the MPNS to measure the menstrual hygiene experience of university students. With MPNS, young girls' needs regarding menstrual hygiene and practices will be determined, and nursing planning can be done in line with the results of the scale. Using this scale in further research will contribute to its effectiveness. ${ }^{22,23}$

\section{Limitations}

One of the limitations was that this study was conducted in only one university in Istanbul in Turkey. Because our study was conducted at a single university in the city center, it cannot be generalized to the general population. We should note that there is no scale with similar content in Turkish, so this scale could not be correlated and discussed with another scale.

\section{Results and Recommendations}

MPNS is a special self-report scale that helps young girls assess their ability to manage menstruation and to what extent they meet their needs in the environment. We aimed to provide Turkish literature with a scale to obtain reliable, consistent, and valid data with this study. The Turkish version of the MPNS is a valid and reliable measurement scale in the assessment of selfperceived menstrual hygiene needs and practices. It is recommended that nurses contribute to the elimination of the deficiencies in this issue by providing training on menstruation to both adolescent girls and their mothers, and given that not only knowledge but also attitudes stemming from traditions and customs are effective on the practice, nurses taking part in health education are recommended to consider these issues. Also, it is recommended to test the validity and reliability of this scale in different languages in different countries to investigate the intercultural differences in young girls. Differences in other cities in Turkey can also be researched.

Ethics Committee Approval: Ethical committee approval was received from the Istanbul Medipol University Noninvasive Clinical Research Ethics Committee (approval number:47I-10.06.2020).
Informed Consent: Written informed consent was obtained from all participants who participated in this study.

Peer-review: Externally peer-reviewed.

Author Contributions: Concept - P.I.V., Y.V; Design - P.I.V., Y.V.; Supervision - P.I.V., Y.V.; Resources - P.I.V., Y.V.; Materials - P.I.V., Y.V.; Data Collection and/or Processing - P.I.V., Y.V.; Analysis and/or InterpretationP.I.V., Y.V; Literature Search - P.I.V., Y.V; Writing Manuscript - Y.V; Critical Review - P.I.V., Y.V.

Acknowledgments: We would like to thank all those who participated in this study.

Conflict of Interest: The authors have no conflicts of interest to declare.

Financial Disclosure: The authors declared that this study has received no financial support.

\section{REFERENCES}

I. Hilary OD, Critchley HO, Babayev E, et al. Menstruation: Science and society. Am J Obstet Gynecol. 2020;223(5):624-664. [CrossRef]

2. Hennegan J, Shannon AK, Rubli J, Schwab KJ, Melendez-Torres G. Women's and girls' experiences of menstruation in low- and middle-income countries: A systematic review and qualitative metasynthesis. Plos Med. 2019;16(5):El002803. [CrossRef]

3. Miiro G, Rutakumwa R, Nakiyingi-Miiro J, et al. Menstrual health and school absenteeism among adolescent girls in Uganda (MENISCUS): A feasibility study. BMC Women's Health. 20|8;|8(I):4. [CrossRef]

4. Yadav RN, Joshi S, Poudel R, Pandeya P. Knowledge, attitude, and practice on menstrual hygiene management among school adolescents. J Nepal Health Res Council. 2018;15(3):212-216. [CrossRef]

5. Xu T, Tomokawa S, Gregorio ER, Jr, Mannava P, Nagai M, Sobel H. School-based interventions to promote adolescent health: A systematic review in low- and middle-income countries of WHO Western Pacific Region. PloS One. 2020;15(3):E0230046. [CrossRef]

6. Menstrual Practice Measures. Available at https://www.menstrualpracticemeasures.org/mpns-36/.

7. Dundar T, Ozsoy S. Menstrual hygiene and visually impaired women. J Educ Res Nurs. 2018;15(3):192-195.

8. Hennegan J, Dolan C, Wu M, Scott L, Montgomery P. Measuring the prevalence and impact of poor menstrual hygiene management: A quantitative survey of schoolgirls in rural Uganda. BMJ Open. 2016;6(12):e012596. [CrossRef]

9. Girod C, Ellis A, Andes KL, Freeman MC, Caruso BA. Physical, social, and political inequities constraining girls' menstrual management at schools in informal settlements of Nairobi, Kenya. $J$ Urban Health. 2017;94(6):835-846. [CrossRef]

10. Nabwera HM, Shah $\vee$, Neville R, et al. Menstrual hygiene management practices and associated health outcomes among schoolgoing adolescents in rural Gambia. PloS One. 2021;16(2):e0247554. [CrossRef]

II. Hennegan J, Nansubuga A, Smith C, Redshaw M, Akullo A, Schwab KJ. Measuring menstrual hygiene experience: Development and validation of the menstrual practice needs scale (MPNS36) in Soroti, Uganda. BMJ Open. 2020;10:e03446I. [CrossRef]

12. DeVellis RF. Scale Development: Theory and Applications. Thousand Oaks, CA: SAGE Publications, 2017.

13. Orçan F. Exploratory and confirmatory factor analysis: Which one to use first? J Meas Eval Educ Psychol. 2018;9(4):4l4-42I. [CrossRef]

14. Chapelle CA. Validity in language assessment. In Loewen S, Sato M (eds.): The Routledge Handbook of Second Language Acquisition and Language Testing. New York: Taylor $\bar{d}$ Francis, 2020. 
15. Esin MN. Data collection methods and tools $\bar{\alpha}$ reliability and validity of data collection tools. In Erdoğan S,Nahcivan N,Esin MN (eds.): Research Process, Practice and Critical in Nursing. Vol. 3. Istanbul, Turkey: Nobel Tip Kitabevleri, 2018.

16. Wu ML. SPSS Operation-Questionnaire Statistical Analysis of Practice. Taipei: Wunan, 2012.

17. Güngör D. Psychological measuring instruments development and customization guide. Turk Psychol Artic. 2016;19(38):104-II2.

18. Büyüköztürk Ş. Sosyal Bilimler Için Veri Analizi El Kitabı. Ankara: Pegem Akademi Yayınları, 2008.

19. Karagöz Y. SPSS 23 and AMOS 23 Applied Statistical Analysis. Ankara, Turkey: Nobel Akademik Publishing, 2016.
20. Kula Kartal S, Mor Dirlik E. Historical development of the concept of validity and the most preferred technique of reliability: Cronbach alpha coefficient. J Abant izzet Baysal Univ Educ Fac. 2016;6(4):1865-1879.

21. Schweizer K, Reiß S, Ren X, et al. Speed effect analysis using the CFA framework. Front Psychol. 2019;10:I-II. [CrossRef]

22. Ibrahim H, Sabar Ismail M. The effect of an educational booklet about menstruation on female nursing students' knowledge, practices and beliefs. IOSR J Nurs Health Sci. 2019;8:17-29.

23. Kuhlmann AS, Henry K, Wall LL. Menstrual hygiene management in resource-poor countries. Obstet Gynecol Surv. 2017;72(6):356376. [CrossRef] 